\title{
BMJ Open Developing an individualised cross- sectoral programme based on activities of daily living to support rehabilitation of older adults with hip fracture: a qualitative study
}

\author{
Alice Ropke (D) , ${ }^{1,2}$ Karina Lund, ${ }^{1}$ Camilla Thrane, ${ }^{3}$ Carsten Juhl, ${ }^{1,2}$ \\ Anne-Le Morville
}

To cite: Ropke A, Lund $\mathrm{K}$, Thrane C, et al. Developing an individualised crosssectoral programme based on activities of daily living to support rehabilitation of older adults with hip fracture: a qualitative study. BMJ Open 2021;11:e044539. doi:10.1136/ bmjopen-2020-044539

- Prepublication history and additional supplemental material for this paper are available online. To view these files, please visit the journal online (http://dx.doi.org/10.1136/ bmjopen-2020-044539).

Received 09 September 2020 Accepted 07 May 2021

Check for updates

(C) Author(s) (or their employer(s)) 2021. Re-use permitted under CC BY-NC. No commercial re-use. See rights and permissions. Published by BMJ.

For numbered affiliations see end of article.

Correspondence to

Alice Ropke;

alice.roepke@regionh.dk

\section{ABSTRACT}

Objectives To develop an individualised rehabilitation programme for personal and instrumental activities of daily living (ADL) tasks, enabling older adults with hip fractures to perform ADL safely and independently.

Design Qualitative study inspired by the complex intervention development (Medical Research Council framework phase I) using literature search and research circles.

Settings University Hospital of Copenhagen, Herlev and Gentofte, and Herlev and Gentofte municipalities.

Participants One research circle with seven older adults with hip fractures, and one with seven healthcare professionals (occupational therapists and physiotherapists).

Results Three generic categories were identified: (1) 'Challenge older adults with goal-oriented ADL tasks', (2) 'Implement strategies to enhance independent and safe performance of ADL tasks', and (3) 'Communicate the important information to the target group and across sectors'. A programme was developed and an intervention to enhance usual rehabilitation was designed comprising: an individualised intervention component consisting of five additional therapy sessions; one during hospitalisation, four in the municipality and a follow-up phone call.

Conclusions Engaging and integrating activities into rehabilitation treatment may support rehabilitation. Our study highlighted the need for setting individual goals and challenging older adults with hip fracture by providing guidance in strategies to enhance safe and independent performance of ADL tasks. Furthermore, the need for providing older adults with hip fracture and healthcare professionals with written and oral information about goal setting during the transitional rehabilitation phase was emphasised. Including the perspectives of older adults with hip fracture and healthcare professionals added value to the rehabilitation, and thus ensured an adequate, tangible and implementable rehabilitation programme. Trial registration number This article is the first of three articles inspired by Medicial Research Council guidelines. The next study is a feasibility study with the trial registration: ClinicalTrials.gov ID: NCT03828240. The results are right now being written in article. The
Strengths and limitations of this study

- The development of the rehabilitation programme was based on results from research circles, in collaboration with healthcare professionals and the target population, to ensure cocreation.

- The credibility and trustworthiness of our findings were enhanced by using peer and member checking.

- We recruited participants from one geographical area in Denmark, so findings may not be transferable to other localities.

- Qualitative methods provide in-depth and rich data, but we are unable to generalise these results and a comprehensive process and feasibility evaluation of the Hip Fracture Rehabilitation Programme is needed to test adherence to and compliance with the intervention.

third study is a randomised controlled trial with the trial registration: ClinicalTrials.gov ID: NCT04207788; Preresults.

\section{INTRODUCTION}

Despite positive surgical outcomes, older adults with hip fractures (HF) need rehabilitation to optimise their performance in activities of daily living (ADL). Just one-third regain their prefracture level of physical function and capacity to perform ADL. ${ }^{12}$ For the remaining two-thirds, there is an increased risk of social isolation, depression and reduced quality of life. ${ }^{3-6}$ Studies have reported poor postfracture outcomes and coordination across the healthcare sectors does not always meet frail patients' needs. ${ }^{7}$ Close, continuous and efficient collaboration between different professions and healthcare sectors is essential to provide patient-centred rehabilitation based on the individual's needs, wishes and competences. ${ }^{9}$ Several studies 
support the effect of multidisciplinary rehabilitation of patients with HF, combining nursing care, physiotherapy, occupational therapy and/or social work. ${ }^{10-13}$ Few studies focus on occupation ${ }^{14}$ and improving ADL, ${ }^{71516}$ and how to support the older adult to safely and independently perform ADL tasks. Occupation in this article refers to work and general activity and participation in daily life. ${ }^{14}$ Thus, the use of motor skills and process skills during ADL task performances is named occupational performance. ${ }^{14}$

Thus, the purpose of this study was to gather knowledge of experiences, needs and expectations of rehabilitation from older adults with HF to develop an intervention programme focusing on their ability to safely and independently perform ADL. To develop a sustainable intervention with multiple perspectives from older adults with HF, their families and healthcare professionals (HCP) specifically physiotherapists (PT) and occupational therapists (OT) - are needed. This study is the first step of a forthcoming trial of developing and evaluating a complex intervention for the rehabilitation of older adults with $\mathrm{HF}$ focusing on enabling occupational performance.

\section{Intervention description}

The Template for Intervention Description and Replication (TIDieR) checklist ${ }^{17}$ was used to evaluate the comprehensiveness of the reporting of the cross-sectorial intervention. Furthermore, the Standards for Reporting Qualitative Research (SRQR) checklist ${ }^{18}$ was used to show transparency in all steps in the qualitative research (online supplemental material).

\section{Rationale and theory essential to the intervention}

The intervention was considered a complex intervention with multiple interacting components. The development phase was inspired by the 2008 UK Medical Research Council $^{19}{ }^{20}$ framework for developing and evaluating complex interventions, which presents three steps: (1) identifying the evidence base, (2) identifying/developing theory, and (3) modelling the process and outcomes. Older adults with HF, HCPs, administrators and managers were continuously involved in the development stage. ${ }^{21}$

\section{Identifying the evidence base}

Identifying the evidence and specifying the content of the intervention was formulated based on a literature search carried out in March 2018 with regular updates on MEDLINE, CINAHL and Embase using the search string: (hip fracture AND activity of daily living AND occupational therapy).

Interventions for older adults with HF dependent on support and rehabilitation are often multidisciplinary. ${ }^{12}$ The organisation and implementation of rehabilitation services varies in length and content, but usually includes occupational therapy and physical therapy. ${ }^{102}$ The positive outcome would be a reduced need of home care and improved occupational performance. ${ }^{23}$ Studies on occupational performance have shown that interventions focused on ADL results reduced dependency in (personal) PADL ${ }^{24}$ and (instrumental) IADL. ${ }^{24}{ }^{25}$ Postoperative care after HF focuses on individual techniques for dressing, bathing and adapting the home environment, ${ }^{1516}$ transferring, positioning and postural standing, technical aids for PADL and IADL. ${ }^{26}$ In addition, home visits by an OT assessing home environment provide strategies for early recovery. ${ }^{752627}$ A postdischarge telephone call in a multidisciplinary intervention may be effective in reducing the proportion of fallers. ${ }^{27}{ }^{28}$ Only a few trials focus on providing strategies for safe and independent occupational performance, focusing on the activities most important for the patient's self-care and independence. Sessions included a range of topics, for example, technical aids and instructions related to ADL training, home environment advice, fall prevention, transfer, walking and ADL. ${ }^{726}$ Individualised occupational therapy intervention was found to have advantages in relation to patients' ability, for example, their ability to perform ADL and improvements in perceived health. ${ }^{76}$

\section{Identifying/developing theory}

The theoretical foundation of the intervention was based on a transactional perspective on occupation ${ }^{29-31}$ and inspired the development phase emphasising (1) personcontext relations, and (2) occupation as a continuous response to situational elements. ${ }^{29} 3032$ An important aspect is to recognise that people cannot be separated from their experiences and context in life, emphasising the importance of taking each individual's circumstances into account during rehabilitation. ${ }^{33}$ What to do and how to be occupation-centred during interventions is defined as having (1) an occupation-focused approach concentrating attention on occupation with a proximal focus on, for example, body functions, environment or other contextual factors; and (2) an occupation-based approach which involves occupational performance as part of evaluations or as interventions engaging in, for example, cooking or reading a book. ${ }^{14}$ Ensuring that the intervention is occupation centred, the Occupational Therapy Intervention Process Model (OTIPM) provides a frame for the intervention. The intervention process is depicted as occurring over three phases: evaluation and goal setting, intervention, and re-evaluation. ${ }^{1434} 35$ Identifying a theory to underpin the specific essential intervention is derived from the collaboration between older adults with HF and HCPs.

\section{MATERIALS AND METHODS}

A qualitative participatory design was adopted by applying the research circle method, ${ }^{36}{ }^{37}$ emphasising engagement and collaborative action between older adults with HF, HCPs and researchers. ${ }^{38}$ The research circle process is characterised by mutual reflection and engagement between participants contributing with equal authority to cocreate collective knowledge. Research circles are based on a common theme that is discussed to generate new in-depth knowledge among the included participants. ${ }^{40-42}$ 


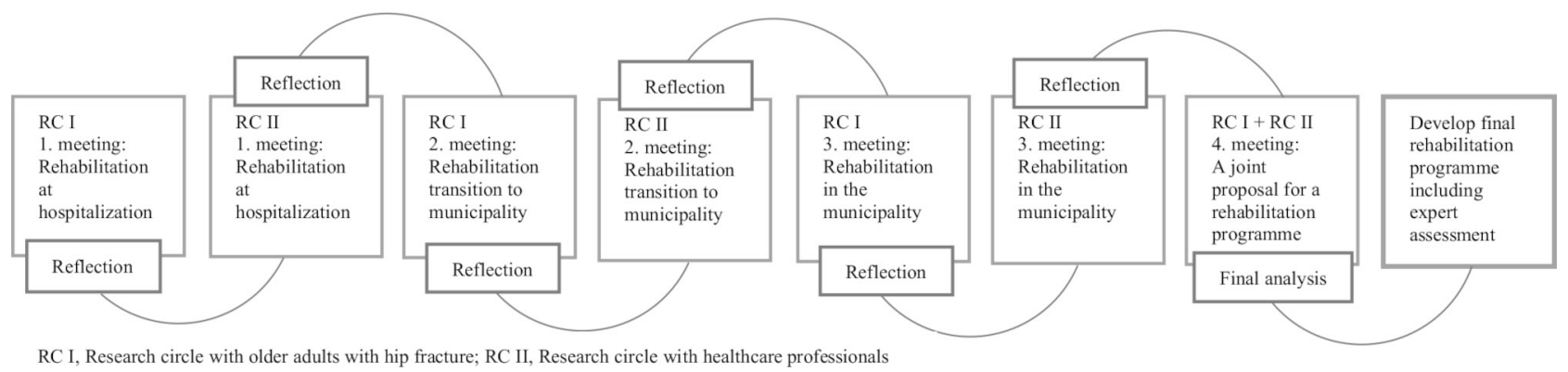

Figure 1 Research circle process with overall topics discussed.

Two research circles were formed: one with older adults with $\mathrm{HF}$, and another with HCPs, OTs and PTs who either work in hospital settings or in municipalities.

The overarching theme for each meeting was determined in advance by AR, the first author, and inspired by the rehabilitation phases in practice developed by Borg ${ }^{43}$ : (1) rehabilitation during hospitalisation, (2) rehabilitation in transition to the municipality, (3) rehabilitation in the municipality, and (4) the resultant collective proposal for a hip rehabilitation programme. At each meeting, an interview guide ${ }^{44}$ was developed based on the respective themes (figure 1).

\section{Sampling and recruitment}

Purposeful sampling was performed to recruit older participants with $\mathrm{HF}$ from a range of postacute settings and demographics, for example, type of housing, geographical district, age and sex. ${ }^{45}$ The HCPs were recruited from Herlev and Gentofte municipality rehabilitation centres and from Copenhagen University Hospital, Herlev and Gentofte (table 1) during the period from February to March 2018.

HCPs at the two municipalities identified potential participants and scheduled dates and times for the research circle meetings for both older adults and the HCPs.

To create a relaxed and trusting atmosphere, the research circles were conducted at the rehabilitation facilities. Prior to the meetings, an email with information about the overall topic for the meetings, time, place and provision of transportation was sent to the participants.

\section{Data collection}

All research circle meetings were conducted between April and June 2018. Two pilot interviews to test the preliminary interview guide were performed: one with an experienced HCP and a group interview with five older adults who had experienced HF rehabilitation. Testing the interview guide, first with the research team and subsequently with potential study participants, ${ }^{46}$ resulted in a reduced number of questions and revision of the interview guide.

Each meeting of the research circle was prepared, recorded and facilitated by two authors, AR and KL (figure 1). Using the interview guide, open-ended questions were asked about the participants' needs, wishes and expectations for individualised occupation-based rehabilitation for adults with HF. The meetings were conducted every third week with older adults and HCPs separately for the first three meetings and together in the last meeting, to share knowledge and ideas gathered from the previous meetings. Each meeting lasted for approximately 2 hours. Between meetings, participants were encouraged to reflect and take notes in a booklet as a resource for discussion at the following meeting. At the end of each meeting, the participants were asked to highlight one idea or statement that they thought important to include in further developing the intervention programme. Summary notes

Table 1 Inclusion and exclusion criteria for older adults with hip fracture

\section{Inclusion criteria}

Aged 55 years or older.

\section{Exclusion criteria}

Not expected to be discharged to home or rehabilitation centres in the municipality.

Not able to speak and/or understand Danish.

Recent proximal hip fracture (S 72.0 medial femur fracture, S 72.1 pertrochanteric femur fracture, $S 72.2$ subtrochanteric femur fracture). Living at home prior to hip fracture in Herlev or Gentofte municipality.
Severe physical and/or mental disabilities prior to the hip fracture.

Ability to give informed consent.

Discharged from hospital and receiving or having received rehabilitation

from the municipalities within the last 3 months from onset.

Inclusion criteria in research circles for healthcare professionals.

At least 2 years of experience with rehabilitation of older adults with hip fracture in the included municipalities or hospital. 
from each meeting were subsequently presented at the next meeting to sustain the continuity of innovations across meetings. The participants were also asked to verify the summaries, thus ensuring they were actively involved in the initial analysis.

\section{Data analysis}

The analysis procedure included two levels and was performed by two authors (AR and KL). Level 1 began after the first meeting of each research circle. The summary of notes taken during the meetings formed the basis of an emerging categorisation of data, confirmed by participants at the end of every meeting. Level 2 of the analysis process involved inductive content analysis performed at a manifest level in three phases as described by Elo and Kyngäs. ${ }^{47}$ During level 2, a third author, ALM, joined the analysis process. In the preparation phase, each of the transcripts was read thoroughly several times to verify its accuracy. The organising phase included open coding, where AR and KL independently highlighted the key statements in the transcripts related to the topics in the interview guides. Using an iterative style, meaning units were then organised and condensed by the two authors using NVivo V.11 Pro. ${ }^{48}$ The analysis moved from lower to higher levels of abstraction, identifying an initial interpretation of patterns, grouping and comparing data in subcategories and categories. A description of the

\section{Sub-category}

- Learn to be oneself as quick as possible

- Urge and follow-up goal-oriented performance of daily tasks

- Surroundings here and there

- Short time to learn

- Apron and nightlight

- Movement restrictions - maybe?

- Deliver, instruct and follow-up on assistive devices
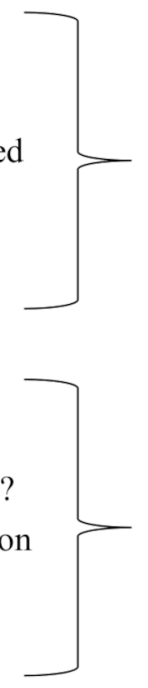

- Information and active involvement in rehabilitation plan

- Clarification of network

- Confusion about transitional hip fracture rehabilitation

- Need for coherent support

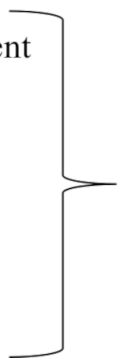

subcategories and categories was then articulated during the reporting phase. The authors explored similarities and differences in the analysis during meetings, which facilitated the development of categories and patterns that best illustrated the needs, expectations and experiences of the participants. ${ }^{49}$ Subcategories emerged and finally the abstraction to generic categories was performed. The process is shown in figure 2.

\section{Patient and public involvement}

One of the strengths of this study has been the involvement of the patient and public representatives in the overall study design from the start. From the initial idea raised at a cross-sectoral workshop with HCP involvement of patients and HCPs providing input, to content of the intervention for the final Hip Fracture Rehabilitation Programme (HIP-REP) manual and on the choice of outcome measures, both patients and the public have been involved. Afterwards, all participants of the patient and public representatives were invited to review and comment on the draft of HIP-REP manual, and thus formed an important part of assessing acceptability of the intervention. Two coauthors on this paper were key members of the research team and contributed to the development and refinement of the content for the HIPREP manual and manuscript revision.

\section{Generic category}
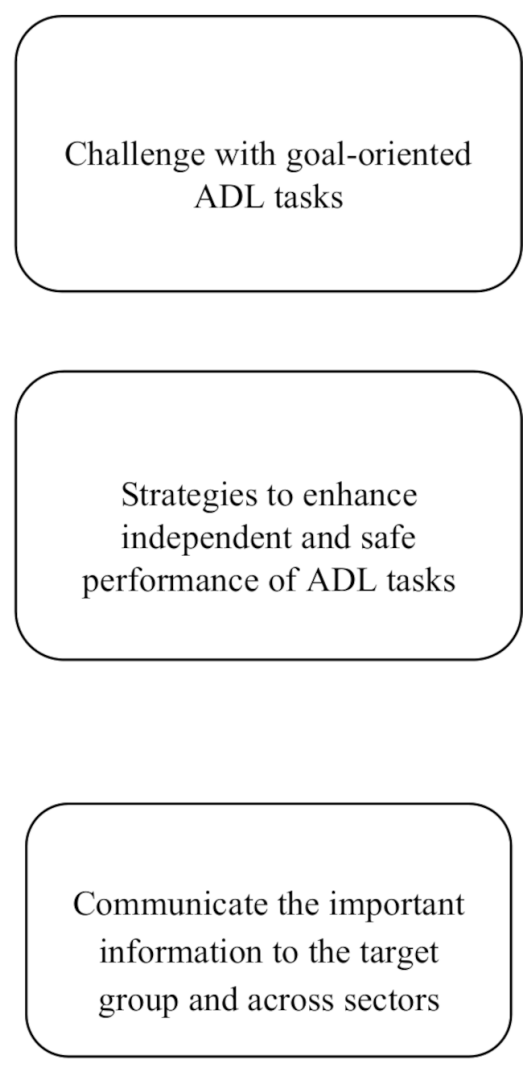

Figure 2 Analysis process: abstraction of subcategory to generic category. ADL, activities of daily living. 
Table 2 Demographic data of the participants in research circles $(n=14)$

\begin{tabular}{lllll}
\hline Older adults & Female & Male & Age (range) & Living situation (range) \\
\hline$(n=7)$ & 6 & 1 & $58-93$ & 5 living alone \\
\hline Healthcare professionals & Physiotherapist & Occupational therapist & Years of experience (range) \\
\hline$(n=7)$ & 3 & 4 & $2-25$ \\
\hline
\end{tabular}

\section{RESULTS}

Identifying a theory to underpin the specific essential intervention elements

A total of 14 participants were included in the research circles: four OTs, three PTs and seven older people with HF (six females and one male). Table 2 summarises the demographic data of the older adults and HCPs.

Though the groups faced their own unique challenges, older adults and the HCPs shared experiences, needs and ideas for a transitional rehabilitation programme, which led to the identification of three generic categories: (1) challenge older adults with goal-oriented ADL tasks, (2) implement strategies to enhance an independent and safe performance of ADL tasks, and (3) communicate the information to the target group and across healthcare sectors (figure 2).

Each generic category extracted from the data is summarised and supported with quotes. The supporting quotes will indicate which of the research circle meetings the quote was extracted from, the research circle, group and number (eg, RCOHF01).

\section{Challenge older adults with goal-oriented ADL tasks}

All participants emphasised the importance of older adults with HF being challenged to perform PADL and IADL tasks and the importance of challenging the older adults from day 1 after surgery.

However, due to the influence of medication, pain and lack of sleep and food during the hospital stay, several of the older adults with HF lacked confidence in ambulation, physical and ADL abilities when discharged:

... if you start during the 8 days (at the Hospital), before going to the Rehabilitation Centre, and you were activated all you were able to, to show what you are capable of...but they forget that the patient has to be challenged...they should activate us as much as possible. (L1, female patient, RCOHF01)

They suggested individual ADL tasks (eg, preparing and eating fresh fruits, washing hands and face, brushing teeth by the sink) matching older adults, for example, in relation to capacity and wanted a focus on PADL goals while in the hospital. After discharge from hospital, more complex domestic and social ADL tasks were asked for by older adults. For example, early independence and safety in walking to the bathroom and managing toileting and bathing to gain previous levels of function:

We want to learn to be ourselves again. As quickly as possible! (W4, female participant, RCOHF02)
Implement strategies to enhance independent and safe performance of $A D L$ tasks

All participants emphasised 'implement strategies to enhance independent and safe performance of ADL tasks'. Older adults raised the issue of their reliance on mobility devices from day 1 and in the following weeks or even months, as this limited their ability to perform ADL tasks. They emphasised the importance of the timing of introduction and graduation of the use of a rollator, walker and/or crutches. Strategies and ideas for carrying objects over short distances were discussed, for example, using an apron with pockets or crossbody bag for carrying a mobile phone and/or snacks/beverage:

...I used a crutch indoors. So, if I want to carry anything I must run back and forth 17 times you know, because I can only carry one thing at a time right, but then you can use an apron to put things in the front pocket. (LI, female patient, RCOHF03)

Additionally, being presented with small assistive devices (eg, sock aid, long handled reacher, etc) several times was indicated as necessary both during hospital stay and at follow-up in the municipality:

I was able to arrange a visit where they (OT) brought a stocking aid, that was great. It was fabulous...she gave me this and one, two, three, I could use it myself. (W4, female patient, RCOHF04)

Communicate the important information to the target group and across sectors

The final category that emerged was the lack of information and communication across healthcare sectors. Organisational changes in workflow are not always passed on to HCPs across sectors, that is, new procedures regarding instructions in movement restrictions or new guidelines regarding rehabilitation services in the municipalities.

...we can't promise the older adult at the hospital anything in regard to future rehabilitation in the municipality before we are sure of their options. (P02, clinical specialist OT, RCHCP02)

Furthermore, older adults with HF wanted general knowledge, such as a booklet about what to expect during and after the operation and during rehabilitation phases, such as information concerning the operation method, normal physical reactions after HF surgery, restrictions and how these could influence a person's occupational performance. 
The importance and dependence on the older adult's social network were evident when gathering information and planning the rehabilitation. Several of the older adults with HF emphasised that they were dependent on family and friends to support basic ADL tasks, both at home and at the rehabilitation centre.

I think it is important that the HCP at the hospital pays attention to whether there is any network no matter how old you are... (S4, clinical specialist PT, RC0401)

Older adults with experience from a rehabilitation centre emphasised the importance of a home visit prior to discharge, to identify potential barriers and minimise the fear of returning home. Furthermore, both older adults and HCP expressed the need for a home visit within 1-3 working days after discharge directly from the hospital or the rehabilitation centre to their home to resolve issues associated with their home environment and plan their individual rehabilitation.

A visit to the home provides valuable information about how older adults function outside the rehabilitation setting. Maybe older adults need a rail in the bathroom, or the carpet needs to be removed or nightlights need to be set up. So, whatever caused the fall, you go through the environment, removing obstacles so they will feel safer at home. (ML1, clinical specialist OT, RCHCP01).

\section{Modelling process and outcomes}

\section{A first draft of an intervention manual and expert review}

The processes and outcomes were modelled as recommended by Sermeus. ${ }^{50}$ The first author drafted a detailed intervention manual using the $\mathrm{TIDieR}^{17}$ checklist and SRQR checklist. ${ }^{18}$

The occupation-centred framework for conceptualising the HIP-REP is based on the OTIPM ${ }^{14}$ and focuses on occupation and approaches identified as: an occupationbased approach, an occupation-focused approach or both.

Following the development of a draft for the manual of the HIP-REP, it was commented on by an impartial rehabilitation expert with knowledge and experience with older adults with HFs and in the development of complex interventions. Furthermore, participants from the research circles all agreed to read and comment on the draft of the manual for the HIP-REP to verify the content, and thus verify the relevance and expected feasibility of its implementation.

\section{The development of the HIP-REP}

The qualitative data were used to develop an overarching working theory: The following will lead to safer and more independent performance of ADL tasks: (1) challenging older adults with HF with goal-specific ADL tasks through an individually tailored goal-oriented programme increasing the complexity of ADL tasks in addition to usual rehabilitation, and (2) increasing the coordination and information of services between sectors delivering rehabilitation across sectors.

The working theory was discussed with researchers in the field of health science and from this, aims and ideas for the intervention were derived. The three generic categories and the working theory led to the following elements: inspiration sheets (occupation-focused and occupation-based activities), worksheets, information sheets and pamphlets (see online supplemental file $1)$. The elements were then framed according to the OTIPM $^{51}$ process and reorganised into the HIP-REP (table 3). The HIP-REP focuses on an individual adaptation of the programme and increasing the complexity of ADL tasks with the goal of returning to an independent and safe performance of relevant tasks (table 4).

\section{A first draft of an intervention manual and expert review Programme structure}

The HIP-REP consists of three phases over a total of 8 weeks (table 4) supervised by OTs: preliminary interviews, baseline tests, five interventions focusing on $\mathrm{ADL}$ that each lasts a minimum of 1 hour and a maximum of 2 hours (including transport and registration for the HCP) and a follow-up phone call at 10 weeks postoperatively. Due to different structures in the municipalities, the HIPREP was divided into a 'two-way track' after discharge from hospital. Both tracks applied four interventions in the municipality undertaken in agreement with the older adults. Track 1 involved older adults being transferred directly to their own home. Track 2 involved older adults staying at a rehabilitation centre before discharge to their home. In both tracks, the intervention was scheduled in collaboration with the older adults as shown in table 4 . When discharged from either hospital or rehabilitation centre, visits to the older adult's own home were to be carried out between the first and third weekdays after returning home.

\section{Programme content}

The content of the HIP-REP is standardised and guided by a manual (table 4) but individually tailored for older adults, and the intervention thus varies in the content and complexity of ADL tasks, based on older adults' priorities, their type of HF and surgical fixation. The OTIPM ${ }^{34}$ guides the HIP-REP, with focus on occupational performance for both intervention and evaluation as described in the manual (full version in Danish available from authors on request). In general, for each intervention, the following elements appear: (1) interview, assessment and identification of problems and/or change in the occupational performance, (2) the intervention phase with implementation of tailored, purposeful activities for performing ADL tasks, (3) the reassessment phase with an initial interview to identify older adults' meaningful pre-HF activities. Inspiration and information material and worksheets were prepared for each session with older adults. 
Table 3 Intervention elements incorporated in the HIP-REP

\section{Intervention \\ process Specification How}

Inform and assess. Inform about the intervention. Older adults with HF

- HIP-REP informing the older adult about the plan for cross-sectional intervention.

- Booklet handed out to the older adult for the recording of information and patient-held ADL goal setting.

- Exploration of possible activity areas to perform ADL tasks: hospital, rehabilitation centre, own home.

HCPs

- OTIPM-inspired worksheet.

Clarify the older adult's

HCPs

client-centred performance. Interview the older adult and other HCPs.

- Review of existing documentation.

- Identify aspect that supports and limits the occupational performance: personal, physical, social and institutional surroundings.

Describe older adults'
self-reported strength and
problems with activity
performance.

Describe which task the older adult prioritises as a focus during assessment and intervention.

\section{HCPs}

- Interview the older adult with HF.

Older adults with HF

- Decide and prioritise possible ADL tasks at the hospital, rehabilitation centre or at own dwelling.

\section{Older adults with HF}

- Initiate ADL activities; ideas to graduated ADL tasks.

- Strategies for graduated ADL tasks; energy-saving techniques, sleep and bed rest.

\section{HCPs}

- Information: booklet for the older adult; hip fracture procedure, operation type and 'what to expect' symptoms after the operation was handed out.

Observe older adults' task performance and describe older adults' starting point for activity performance.

Clarify and interpret the

\section{HCPs (OT)}

- AMPS assessment of the older adult with HF performing prioritised tasks.

HCPs

reasons older adults reduced To analyse the physical, personal and environmental surroundings of the activity performance.

older adult with HFs.

- Hip fracture information; operation and restriction movements.

- Information and instruction; mobility devices and PADL technical aids for bathing and dressing.

Formulate goals.

\section{Older adults with HF and HCPs}

- Occupation-focused and/or occupation-based goals are formulated; the agreed goals are written in booklets and evaluated at each meeting.

Plan and initiate

intervention.

\section{Older adults with HF and HCPs}

In collaboration, it is decided which intervention to initiate: compensatory, acquisitional model for skills training and/or restorative model for enhancing body functions and other client elements.

- Initiate activities; ideas to graduated ADL tasks.

- Strategies for graduated ADL tasks; energy-saving techniques, sleep and bed rest.

$\begin{array}{ll}\text { Assess the result. } & \begin{array}{l}\text { Observe older adults' task } \\ \text { performance and describe } \\ \text { the new level for activity } \\ \text { performance. }\end{array} \\ \begin{array}{l}\text { Compare the new level of } \\ \text { performance with starting } \\ \text { point and goals. }\end{array} & \text { HCPs }\end{array}$


Table 3 Continued

\begin{tabular}{ll}
\hline $\begin{array}{l}\text { Intervention } \\
\text { process }\end{array}$ & Specification \\
\hline $\begin{array}{l}\text { Decide if the } \\
\text { intervention } \\
\text { continues or ends. }\end{array}$ & $\begin{array}{l}\text { Older adults with HF and HCPs } \\
\text { At the last intervention visit, it is decided if the intervention should } \\
\text { continue or end. }\end{array}$ \\
$\begin{array}{l}\text { End the intervention } \\
\text { process. }\end{array}$ & $\begin{array}{l}\text { Older adults with HF and HCPs } \\
\text { Decide if further intervention is necessary and/or maybe refer to other }\end{array}$ \\
& healthcare-relevant offers in the municipality.
\end{tabular}

Categories from analysis informing the content of the elements in the Hip Fracture Rehabilitation Programme based on OTIPM. ${ }^{51}$

ADL, activities of daily living; AMPS, Assessment of Motor and Process Skills; HCP, healthcare professional; HF, hip fracture; HIP-REP, Hip Fracture Rehabilitation Programme; OT, occupational therapist; OTIPM, Occupational Therapy Intervention Process Model; PADL, personal activities of daily living.

\section{Expert review}

Determining the content validity, an expert ${ }^{44}$ in rehabilitation for older adults with HF suggested structural and content considerations for the programme, for example, a clarification on introduction and education of the OTs participating in the programme and suggesting a clarification of exclusion criteria. There was also a suggestion as to when intervention during hospitalisation could be implemented. The expert reviews, ideas and suggestions were considered and incorporated into manual. The participants in the research circles commented on unclear sentences and spelling mistakes which were corrected in the final manual (table 4).

\section{DISCUSSION}

Our main result was the identification of additional components for the rehabilitation of older adults with HF. It revealed tangible strategies to facilitate the transitional rehabilitation process across sectors. Three generic categories emerged.

\section{Challenge with goal-oriented ADL tasks}

Challenges must fit the individual's expectations, wishes and foremost their capabilities of performing ADL tasks. A previous study showed that such a fit resulted in better outcomes when tailoring the rehabilitation. ${ }^{52}$ Our findings emphasise the importance of involving older adults in the process as soon as possible, to set relevant goals and to promote the experience of confidence and active participation in their rehabilitation. Participants provided insights into what type of occupation they prioritised during the first months after HF, that is, activities performed within their own residence, including social activities. Our findings extend previous research, recognising that identification of individual goals supports the participants in regaining independence and facilitates their recovery process. ${ }^{53}$ In addition, older adults showed an interest in facilitating individualised goals by using a booklet to document and encourage achievement of goals during the transition between care settings and home.

\section{Implement strategies to enhance independent and safe performance of ADL tasks}

Our study showed that older adults often developed their own strategies to enhance independent and safe occupational performance. They used work simplification and energy-saving techniques during the first postoperative weeks, including prioritisation of activities due to lack of energy, adaptation of their environment, use of assistive devices for mobility, bathing and dressing. Their strategies show that relatively simple solutions, such as an apron or a crossbody bag for transport of devices, enabled them to move safely, independently and perform manageable activities. As previous literature reported, the older adult generates individual strategies to overcome the temporary loss of independence and thus manages to live at home after discharge ${ }^{54}$ This shows that the older adult with $\mathrm{HF}$ has a transactional perspective ${ }^{29} 3132$ on their use of strategies taking into account constructs such as person, occupation and context.

\section{Communicate the important information to the target group and across sectors}

There is a trend towards reduction in length of stays at hospital due to early operative treatment. ${ }^{5254}$ This leaves only a few days to accomplish complex aspects of rehabilitation. In our study, the older participants reported that they found that the rapid transition was daunting. The assessment, advice and strategies regarding ADL tasks at the hospital become a challenge before discharge, for example, education in hip precautions, introducing and providing small aids during their stay to become more independent. Langford et a $\tilde{l}^{4}$ described that with regard to ADL, becoming dependent on others causes distress to some older adults, as usual routines are disrupted, and another study ${ }^{55}$ reports a feeling of not being equipped or prepared for the transition. Our study shows the importance of knowing what to expect regarding the 
Table 4 HIP-REP for older adults with hip fracture from first postoperative day to week 12 including five interventions based on occupational performance: one intervention during hospital stay, and four at the rehabilitation centre and/or at home. Home visits must be carried out in both tracks 1 and 2

\begin{tabular}{|c|c|c|c|}
\hline \multicolumn{4}{|c|}{ The progress at the hospital } \\
\hline $\begin{array}{l}\text { Day } \\
\text { postoperative }\end{array}$ & Session & Intervention & Activities \\
\hline Day 1 & 1 st & Inform and identify. & Welcome to the ward. \\
\hline \multirow[t]{2}{*}{ Days $1-2$} & \multirow[t]{2}{*}{ 2nd } & \multirow[t]{2}{*}{ Inform and identify. } & Initial interview. \\
\hline & & & $\begin{array}{l}\text { Interview-prioritise two } \\
\text { ADL tasks for AMPS. }\end{array}$ \\
\hline \multirow[t]{2}{*}{ Day 3} & \multirow[t]{2}{*}{$3 r d$} & \multirow[t]{2}{*}{$\begin{array}{l}\text { Inform and identify. } \\
\text { Objectives, planning and } \\
\text { implementation. }\end{array}$} & $\begin{array}{l}\text { Observation: AMPS, as well } \\
\text { as clarifying and interpreting } \\
\text { cause and discussing } \\
\text { objectives. }\end{array}$ \\
\hline & & & $\begin{array}{l}\text { Hip fracture information; } \\
\text { operation, restriction } \\
\text { movements handed out. }\end{array}$ \\
\hline \multirow[t]{2}{*}{ Days 3-4 } & \multirow[t]{2}{*}{ 4th } & 1st ADL intervention. & $\begin{array}{l}\text { PADL and IADL tasks at the } \\
\text { ward prioritised by older } \\
\text { adult. }\end{array}$ \\
\hline & & $\begin{array}{l}\text { Inform and identify, goal } \\
\text { setting, plan, engage and } \\
\text { assess results. }\end{array}$ & \\
\hline Days $4-5$ & 5th & Evaluate and end course. & $\begin{array}{l}\text { Clarify and order assistive } \\
\text { devices. }\end{array}$ \\
\hline
\end{tabular}

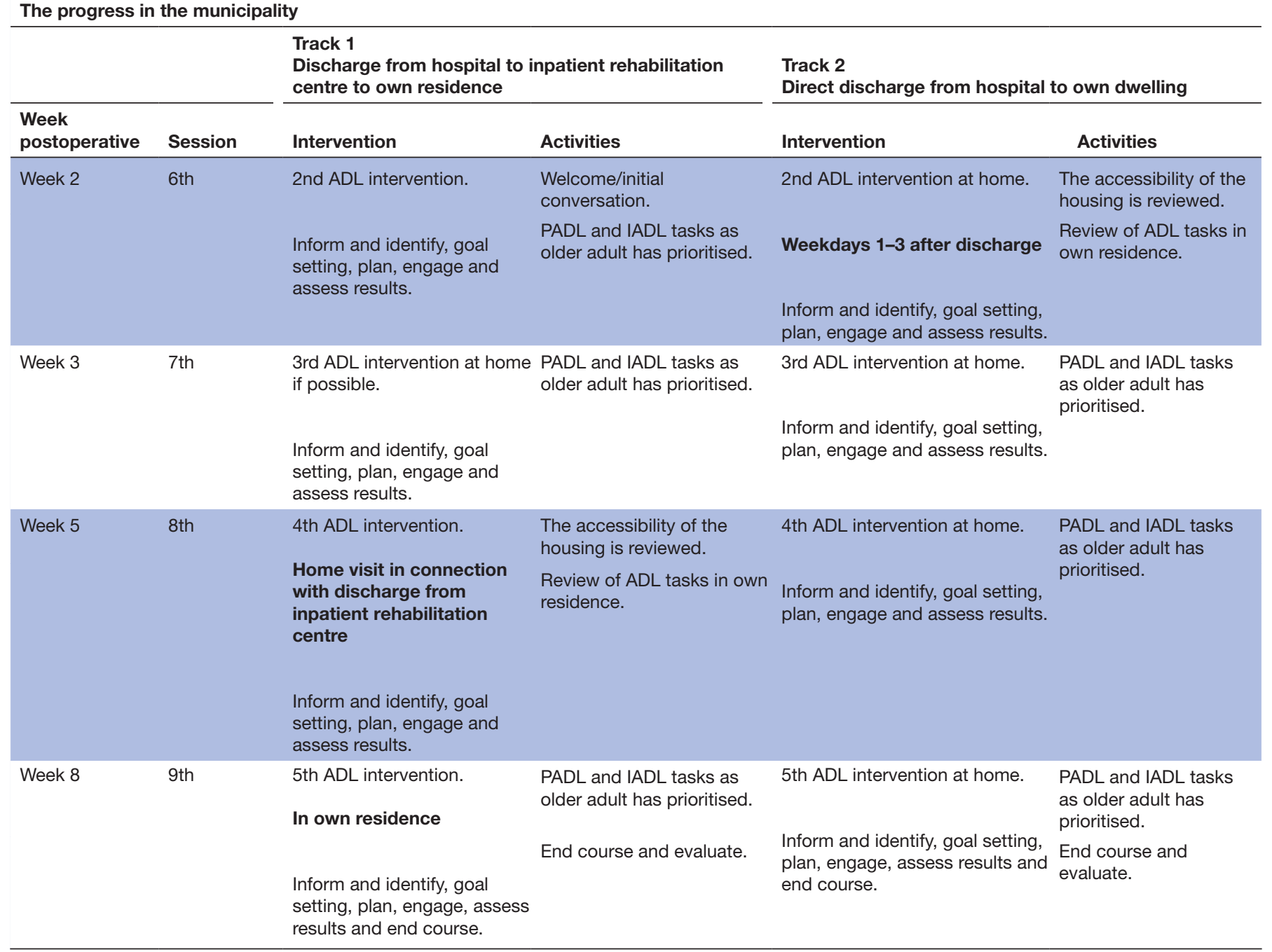




\begin{tabular}{|c|c|c|c|c|c|}
\hline \multicolumn{6}{|c|}{ The progress in the municipality } \\
\hline \multirow[b]{2}{*}{$\begin{array}{l}\text { Week } \\
\text { postoperative }\end{array}$} & \multirow[b]{2}{*}{ Session } & \multicolumn{2}{|c|}{$\begin{array}{l}\text { Track } 1 \\
\text { Discharge from hospital to inpatient rehabilitation } \\
\text { centre to own residence }\end{array}$} & \multicolumn{2}{|c|}{$\begin{array}{l}\text { Track } 2 \\
\text { Direct discharge from hospital to own dwelling }\end{array}$} \\
\hline & & Intervention & Activities & Intervention & Activities \\
\hline Week 12 & 10th & Evaluate. & Evaluate. & Evaluate. & Evaluate. \\
\hline
\end{tabular}

ADL, activities of daily living; AMPS, Assessment of Motor and Process Skills; HIP-REP, Hip Fracture Rehabilitation Programme; IADL, instrumental activities of daily living; PADL, personal activities of daily living.

rehabilitation and also the need of focusing on ADL tasks during hospitalisation, at the rehabilitation centre and at home. This applies especially to older adults living alone with HF, a point that was emphasised both by HCPs and older adults, as those people are more vulnerable and have greater need for information prior to discharge. Social support from family and friends has been reiterated in other studies as important ${ }^{5356}$ to assist with practical arrangements, and to motivate, encourage and give emotional support. Providing patients with a 'recovery map' including information about the HF operation and which symptoms to expect, forthcoming appointments and other resources could be beneficial, suggesting that written patient-centred information enhances knowledge and facilitates decision-making and recovery. ${ }^{57} 58$ This stresses the importance of the HCP's role in supporting more effective communication, involving and informing older adults with $\mathrm{HF}$ and their relatives across professions and settings. ${ }^{59-61}$ Participants in our study found the transition from the hospital or rehabilitation centre to their own home as critical. They found that home visits prior to discharge and after discharge that were carried out to assess and/or modify environmental barriers in the home improved occupational performance and reduced the risk of falling. This is consistent with results from other studies involving older people with functional limitations in hospital discharge planning. Furthermore, including home visits has been shown to result in reduced readmission, risk of falls and improved functional performance. ${ }^{6162}$

\section{Methodological considerations}

Our study has some limitations as it only includes two professions in the research circles out of a broader interdisciplinary team. However, the HCPs were experienced and conscious of this and responded from the perspective of the broader team. At the last research circle meeting, no additional insights or understandings were collected, indicating saturation was obtained in the research circles. ${ }^{44}$ The use of research circles did not aim for a deeper analysis of feelings and emotions, but provided a participatory focus, making it possible to collaborate with older adults and HCP participants throughout the research process, supporting the development and gaining new knowledge together through reflection. . $^{3} 3940$

The study excluded older adults with severe cognitive impairments or difficulty in communicating in Danish, which may limit the use of the results and the intervention may therefore need to be adapted to other patient groups.

The credibility and trustworthiness of our findings were enhanced by using peer and member checking, ${ }^{44}$ independent coding and experts' views on the draft of the HIP-REP. This was enabled by ensuring that all participants would feel comfortable sharing ideas and information during the meetings in an open and supportive environment. To ensure credibility, transparency in the analysis phase using steps recommend by Elo and Kyngäs was followed as well as using quotes to emphasise the similarities and differences in the categories. ${ }^{47}$

\section{CONCLUSIONS}

Our study highlighted the need to setting individual goals and challenging older adults with HF by providing guidance in strategies to enhance safe and independent performance of ADL tasks. Furthermore, the need for providing older adults with HF and HCP written and oral information about goal setting during the transitional rehabilitation phase was emphasised. Including the perspectives of older adults with HF and HCPs added value to the HIP-REP, and thus ensured an adequate, tangible and implementable rehabilitation programme.

\section{Author affiliations}

${ }^{1}$ Department of Physiotherapy and Occupational Therapy, Copenhagen University Hospital, Herlev and Gentofte, Copenhagen, Denmark

${ }^{2}$ Department of Sports Science and Clinical Biomechanics, University of Southern Denmark, Odense, Denmark

${ }^{3}$ Health Promotion and Rehabilitation, Municipality of Herlev, Herlev, Denmark ${ }^{4}$ ADULT Research Group, Department of Rehabilitation, School of Health and Welfare, Jönköping University, Jönköping, Sweden

Acknowledgements The authors thank the participants for sharing their insights and time with the research team. Furthermore, we want to thank the two rehabilitation centres and the University Hospital for their collaboration and for making their facilities available for researchers while conducting the research 
circles, and clinical professor Morten Tange Kristensen for his input and feedback on the first HIP-REP draft.

Contributors Study planning, conception and design: AR, KL, CT, CJ, ALM. Drafting the work or revising it critically for important intellectual content: AR, KL, CT, CJ, ALM. Acquisition of data: AR. Analysis and interpretation of data: AR, KL, CT, CJ, ALM. Final approval of the version published: AR, KL, CT, CJ, ALM.

Funding This study was funded by the Region's Research and Development Fund (R26-1121); the Intersectoral Research Unit (P-2017-1-11; P-2019-2-16); University College Copenhagen, Department of Physiotherapy and Occupational Therapy (internal funding), University Hospital Copenhagen, Herlev and Gentofte (internal funding) and the Occupational Therapists Association (FF2-R104-A2093).

\section{Competing interests None declared.}

Patient consent for publication Not required.

Ethics approval The study followed the Danish legislation regarding ethics in scientific studies and was approved by the Ethics Committees ( $\mathrm{H}-18000881)$ and the Danish Data Protection Agency (journal number: 2012-58-0004).

Provenance and peer review Not commissioned; externally peer reviewed.

Data availability statement Data are available upon reasonable request. HIP-REP manual in Danish and data used during the current study are available from the corresponding author on reasonable request.

Supplemental material This content has been supplied by the author(s). It has not been vetted by BMJ Publishing Group Limited (BMJ) and may not have been peer-reviewed. Any opinions or recommendations discussed are solely those of the author(s) and are not endorsed by BMJ. BMJ disclaims all liability and responsibility arising from any reliance placed on the content. Where the content includes any translated material, BMJ does not warrant the accuracy and reliability of the translations (including but not limited to local regulations, clinical guidelines, terminology, drug names and drug dosages), and is not responsible for any error and/or omissions arising from translation and adaptation or otherwise.

Open access This is an open access article distributed in accordance with the Creative Commons Attribution Non Commercial (CC BY-NC 4.0) license, which permits others to distribute, remix, adapt, build upon this work non-commercially, and license their derivative works on different terms, provided the original work is properly cited, appropriate credit is given, any changes made indicated, and the use is non-commercial. See: $\mathrm{http}: / /$ creativecommons.org/licenses/by-nc/4.0/.

\section{ORCID iD}

Alice Ropke http://orcid.org/0000-0001-7793-5558

\section{REFERENCES}

1 Giannoulis D, Calori GM, Giannoudis PV. Thirty-day mortality after hip fractures: has anything changed? Eur J Orthop Surg Traumatol 2016;26:365-70.

2 Le Manach Y, Collins G, Bhandari M, et al. Outcomes after hip fracture surgery compared with elective total hip replacement. JAMA 2015;314:1159.

3 González-Zabaleta J, Pita-Fernandez S, Seoane-Pillado T, et al. Dependence for basic and instrumental activities of daily living after hip fractures. Arch Gerontol Geriatr 2015;60:66-70.

4 Alarcón T, González-Montalvo JI, Gotor P, et al. Activities of daily living after hip fracture: profile and rate of recovery during 2 years of follow-up. Osteoporos Int 2011;22:1609-13.

5 Orive M, Aguirre U, García-Gutiérrez S, et al. Changes in healthrelated quality of life and activities of daily living after hip fracture because of a fall in elderly patients: a prospective cohort study. Int $J$ Clin Pract 2015;69:491-500.

6 Sirkka M, Brãnholm I-britt, Bränholm I. Consequences of a hip fracture in activity performance and life satisfaction in an elderly Swedish clientele. Scand J Occup Ther 2003;10:34-9.

7 Hagsten B, Svensson O, Gardulf A. Early individualized postoperative occupational therapy training in 100 patients improves ADL after hip fractureA randomized trial. Acta Orthop Scand 2004;75:177-83.

8 Beaupre LA, Carson JL, Noveck H, et al. Recovery of walking ability and return to community living within 60 days of hip fracture does not differ between male and female survivors. J Am Geriatr Soc 2015;63:1640-4.

9 Valentiner LS, Steen R. Genoptræningsforløbsbeskrivelse for hoftenært brud. Tværsektoriel genoptræningsforløbsbeskrivelse (In Danish). Region Hovedstaden: Den Administrative Styregruppe i Region Hovedstaden, 2014.
10 Zidén L, Frändin K, Kreuter M. Home rehabilitation after hip fracture. A randomized controlled study on balance confidence, physical function and everyday activities. Clin Rehabil 2008;22:1019-33.

11 Crotty M, Killington M, Liu E, et al. Should we provide outreach rehabilitation to very old people living in nursing care facilities after a hip fracture? a randomised controlled trial. Age Ageing 2019;48:373-80.

12 Prestmo A, Hagen G, Sletvold O, et al. Comprehensive geriatric care for patients with hip fractures: a prospective, randomised, controlled trial. Lancet 2015;385:1623-33.

13 Lahtinen A, Leppilahti J, Harmainen S, et al. Geriatric and physically oriented rehabilitation improves the ability of independent living and physical rehabilitation reduces mortality: a randomised comparison of 538 patients. Clin Rehabil 2015;29:892-906.

14 Fisher AG. Occupation-centred, occupation-based, occupationfocused: same, same or different? Scand J Occup Ther 2013;20:162-73.

15 Hagsten B, Svensson O, Gardulf A. Health-Related quality of life and self-reported ability concerning ADL and IADL after hip fracture: a randomized trial. Acta Orthop 2006;77:114-9.

16 Martín-Martín LM, Valenza-Demet G, Ariza-Vega P, et al. Effectiveness of an occupational therapy intervention in reducing emotional distress in informal caregivers of hip fracture patients: a randomized controlled trial. Clin Rehabil 2014;28:772-83.

17 Hoffmann TC, Glasziou PP, Boutron I, et al. Better reporting of interventions: template for intervention description and replication (TIDieR) checklist and guide. BMJ 2014;348:g1687.

18 O'Brien BC, Harris IB, Beckman TJ, et al. Standards for reporting qualitative research: a synthesis of recommendations. Acad Med 2014;89:1245-51.

19 Fraser MW, Galinsky MJ. Steps in intervention research: designing and developing social programs. Res Soc Work Pract 2010;20:459-66.

20 Craig P, Dieppe P, Macintyre S, et al. Developing and evaluating complex interventions: the new medical Research Council guidance. BMJ2008;337:a1655.

21 Richards D. The critical importance of patient and public involvement. In: Richards DHI, ed. Complex interventions in health: an overview of research methods. 1st ed. Oxon and New York: Routledge, 2015: p. 46.

22 Roberts JL, Din NU, Williams M. Development of an evidence-based complex intervention for community rehabilitation of patients with hip fracture using realist review, survey and focus groups. BMJ Open2017;7:e014362.

23 Whitehead PJ, Walker MF, Parry RH, et al. Occupational therapy in HomEcare Re-ablement services (others): results of a feasibility randomised controlled trial. BMJ Open 2016;6:e011868-e68.

24 Cook RJ, Berg K, Lee K-A, et al. Rehabilitation in home care is associated with functional improvement and preferred discharge. Arch Phys Med Rehabil 2013;94:1038-47.

25 Lewin G, De San Miguel K, Knuiman M, et al. A randomised controlled trial of the home independence program, an Australian restorative home-care programme for older adults. Health Soc Care Community 2013;21:69-78.

26 Martín-Martín LM, Valenza-Demet G, Jiménez-Moleón JJ, et al. Effect of occupational therapy on functional and emotional outcomes after hip fracture treatment: a randomized controlled trial. Clin Rehabil 2014;28:541-51

27 Di Monaco M, Vallero F, De Toma E, et al. A single home visit by an occupational therapist reduces the risk of falling after hip fracture in elderly women: a quasi-randomized controlled trial. J Rehabil Med 2008;40:446-50.

28 Di Monaco M, De Toma E, Gardin L, et al. A single postdischarge telephone call by an occupational therapist does not reduce the risk of falling in women after hip fracture: a randomized controlled trial. Eur J Phys Rehabil Med 2015;51:15-22.

29 Aldrich RM. From complexity theory to transactionalism: moving occupational science forward in theorizing the complexities of behavior. J Occup Sci 2008;15:147-56.

30 Cutchin MP, Aldrich RM, Bailliard AL, et al. Action theories for occupational science: the contributions of Dewey and Bourdieu. J Occup Sci 2008;15:157-65.

31 Lee Bunting K. A transactional perspective on occupation: a critical reflection. Scand J Occup Ther 2016;23:327-36.

32 Aldrich RM, Cutchin MPCutchin MP, Dickie VA, eds. Dewey's concepts of embodiment, growth, and occupations: Extended bases for a transactional perspectives. New York: Springer, 2013

33 Fisher AG, Marterella A. Powerful Practice - A Model for Authentic Occupational Therapy. Colorado, USA: Center for Innovative OT Solutions, Inc, 2019.

34 Fisher AG. OTIPM. København Munkgaard; 2013. 
35 Fisher AG, Jones KB. Occupational Therapy Intervention Process Model. In: Hinojosa J, Kramer P, Royeen CB, eds. Perspectives on Human Occupation - Theories Underlying Practice. Secon edition. United States of America: F. A. Davis Company, 2017: 237-86.

36 Härnstein G. The Research Circle: Building Knowledge on Equal Terms. Stockholm: Swedish Trade Union Confederation, 1994.

37 Haak M, Slaug B, Oswald F, et al. Cross-National user priorities for housing provision and accessibility - findings from the European innovAge project. Int J Environ Res Public Health 2015;12:2670-86.

38 Iwarsson S, Edberg A-K, Ivanoff SD, et al. Understanding user involvement in research in aging and health. Gerontology and Geriatric Medicine 2019;5:233372141989778.

39 Reed J, Weiner R, Cook G. Partnership research with older people - moving towards making the rhetoric a reality. J Clin Nurs 2004;13:3-10.

40 Högdin SKC. Research circles: a method for the development of knowlegde and the creation of change in practice. Saber Educar $2014 ; 19$.

41 Östlund B. The revival of research circles: meeting the needs of modern aging and the third age. Educ Gerontol 2008;34:255-66.

42 Persson S. Forskningscirklar - en vägledning. Malmö: Malmö stad, 2008.

43 Borg T. Livsføre/se I hverdagen under rehabilitering. et socialpsykologisk studie (in Danish). Aalborg Universitet, 2002.

44 Depoy E, Gitlin LN. Gathering Information in Naturalistic Inguiry. Introduction to Research - Understanding and Applying Multiple Strategies. 4th ed. St. Louis (USA: Elsevier Mosby, 2011: p. 228.

45 Coyne IT. Sampling in qualitative research; merging or clear boundaries? J Adv Nurs 1997;26:7.

46 Kallio H, Pietilä A-M, Johnson M, et al. Systematic methodological review: developing a framework for a qualitative semi-structured interview guide. J Adv Nurs 2016;72:2954-65.

47 Elo S, Kyngäs H. The qualitative content analysis process. J Adv Nurs 2008;62:107-15.

48 QSR International. Nvivo 11 Pro for Windows [program]. 11.4 version 2017.

49 Richards L. Handling qualitative data. A practical guide. Third ed. Australia: Sage Publication, 2014.

50 Sermeus W. Modelling process and outcomes in complex interventions. In: Richards DHI, ed. Complex interventions in health: an overview of research methods. Oxon and Newe York: Routledge, 2015: p.111.

51 Fisher A. Appendiks. In: Murmand L, ed. OTIPM Latvia (in Danish). Munksgaard, 2013: p. 209.

52 Young Y, Resnick B. Don't worry, be positive: improving functional recovery 1 year after hip fracture. Rehabil Nurs 2009;34:110-7.

53 Saul D, Riekenberg J, Ammon JC, et al. Hip fractures: therapy, timing, and complication spectrum. Orthop Surg 2019;11:994-1002.

54 Langford D, Edwards N, Gray SM, et al. "Life Goes On." Everyday Tasks, Coping Self-Efficacy, and Independence: Exploring Older Adults' Recovery From Hip Fracture. Qual Health Res 2018;28:1255-66.

55 Toscan J, Manderson B, Santi SM, et al. "Just another fish in the pond": the transitional care experience of a hip fracture patient. Int $J$ Integr Care 2013;13:e023.

56 Taylor NF, Harding KE, Dowling J, et al. Discharge planning for patients receiving rehabilitation after hip fracture: A qualitative analysis of physiotherapists' perceptions. Disabil Rehabil 2010;32:492-9.

57 Schiller C, Franke T, Belle J, et al. Words of wisdom - patient perspectives to guide recovery for older adults after hip fracture: a qualitative study. Patient Prefer Adherence 2015;9:57-64.

58 Jensen CM, Smith AC, Overgaard S, et al. "If only had I known": a qualitative study investigating a treatment of patients with a hip fracture with short time stay in hospital. Int J Qual Stud Health Wellbeing 2017;12:1307061.

59 Asif M, Cadel L, Kuluski K, et al. Patient and caregiver experiences on care transitions for adults with a hip fracture: a scoping review. Disabil Rehabil 2020;42:3549-58.

60 Coleman EA. Falling through the cracks: challenges and opportunities for improving transitional care for persons with continuous complex care needs. J Am Geriatr Soc 2003;51:549-55.

61 Lockwood KJ, Harding KE, Boyd JN, et al. Predischarge home visits after hip fracture: a randomized controlled trial. Clin Rehabil 2019;33:681-92.

62 Stark S, Keglovits M, Arbesman M, et al. Effect of home modification interventions on the participation of community-dwelling adults with health conditions: a systematic review. Am J Occup Ther 2017;71:1-11. 